Geografia e Ordenamento do Território, Revista Eletrónica

Centro de Estudos de Geografia e Ordenamento do Território

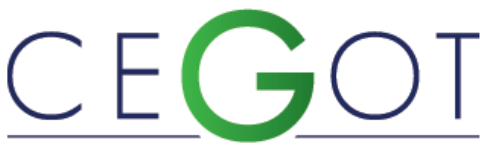

Centro de Estudos de Geografia

e Ordenamento do Território http://cegot.org

ISSN: 2182-1267

Silva, E.

Universidade Federal do Rio Grande do Norte (Brasil)

eugenio_geo@yahoo.com.br

\title{
O Planejamento Estratégico sem plano: uma análise do empreendedorismo urbano no Brasil ${ }^{1}$
}

Referência: Silva, E. R.. (2012). O Planejamento Estratégico sem plano: uma análise do empreendedorismo urbano no Brasil. Revista de Geografia e Ordenamento do Território, n.o 2 (Dezembro). Centro de Estudos de Geografia e Ordenamento do Território. Pág. 279 a 306

\section{Resumo}

O modelo de planejamento estratégico de cidades chega à América Latina, passando a ser adotado em cidades brasileiras, com a formulação de planos estratégicos, desde a década de 1990. Em muitas cidades, porém, o padrão de produção da cidade não se deu de acordo com o modelo adotado internacionalmente, mas desenvolveram uma espécie de "planejamento estratégico sem plano" ou "empreendedorismo periférico", no qual buscam construir atributos para qualificarem sua inserção no cenário competitivo internacional e regional, através da imitação de outros centros urbanos.

\footnotetext{
${ }^{1}$ Agradeço as orientações, críticas e sugestões do prof. Dr. Márcio Moraes Valença a esse trabalho.
} 
Palavras-chave: Planejamento estratégico de cidades, empreendedorismo urbano periférico, cidades brasileiras, imitação

\begin{abstract}
The model of strategic city planning is applied to Latin American and Brazilian cities since the 1990s. Notwithstanding, in many cities, the production of space has not followed the international model stricto sensu, but a variation of the model, here called, 'strategic city planning without a plan' or 'peripheral (or yet incomplete) urban entrepreneurialism'. This seeks to build city attributes in order to qualify cities for the competitive international and/or regional markets, through imitation of other urban centers.
\end{abstract}

Keywords: Strategic city planning, peripheral urban entrepreneurialism, brazilian cities, imitation 


\section{Introdução}

Estratégia é uma palavra que vem do grego antigo stratègós, que remete a ciência das operações militares. Tem a ver com liderança, comando, a arte do general. Planejamento estratégico, por sua vez, é um termo cunhado pela administração, na lógica da complexidade das empresas, significando "medidas positivas que uma empresa poderá tomar para enfrentar ameaças e aproveitar as oportunidades encontradas em seu ambiente" (Alday, 2000, p. 10). A estratégia foi incorporando-se paulatinamente no vocabulário da administração, sobretudo após a Segunda Guerra Mundial, e foi ganhando espaço através de diversas abordagens da administração. 0 clima era de competição internacional entre as empresas, e os lugares deveriam estar preparados para fomentarem um ambiente adequado para que as empresas se tornassem mais competitivas (Lima Júnior, 2003). Apesar das várias escolas de planejamento estratégico, "todas elas têm como origem o modelo desenvolvido pela Havard Business School que desde 1920 incluía ações estratégicas no seu curso de política de negócios" (Lopes, 1998, p. 80).

O planejamento estratégico teve o seu uso generalizado para a administração pública quando Margareth Thatcher esteve no comando do Reino Unido, a partir de 1979. Contudo, os projetos de reconversão urbana tem uma história anterior, já que:

\footnotetext{
Iniciou-se nos Estados Unidos da América, no final dos anos cinquenta, nas cidades de Baltimore e Boston. As cidades canadianas de Toronto e Montreal não tardaram a empreender projetcos semelhantes e, nos anos oitenta, Londres inaugura uma série de experiências europeias com o célebre projecto das Docklands (Branco-Teixeira, 1999).
}

Baltimore é um dos casos mais estudados de reconversão urbana dos Estados Unidos da América, através das intervenções no waterfronts. No contexto do fim da Segunda Guerra Mundial e com uma crise econômica, a referida cidade experimentava um verdadeiro abandono de edifícios na área central, com uma sub-utilização do porto e uma marginalidade crescente. Esse quadro foi mudado com a união de um grupo de cidadãos influentes da cidade que iniciou um conjunto de medidas estratégicas para recuperar alguns edifícios históricos, no intuito de estimular o soerguimento do 
comércio e serviços. Como o contexto era liberal, foi possível fazer parceria entre os setores público e privado, cujos projetos foram essenciais para alcançar o sucesso econômico da cidade, resultando até na criação de 30.000 postos de trabalho (BrancoTeixeira, 1999).

Outro caso importante de reconversão urbana no waterfronts é o de Boston, o qual contou também com uma parceria entre as esferas público e privada em meados da década de 1960. As autoridades públicas tiveram um papel importante no processo de reconversão, obtendo "significativas contrapartidas dos investidores privados" (Branco-Teixeira, 1999, p. 88).

Na Europa, um emblemático caso de reconversão urbana é o das Docklands, em Londres. Essa área que, como as norte-americanas, experimentava um abandono a partir do desemprego e da crescente diminuição da população, viu no sucesso das reconversões americanas a oportunidade de sair dessa crise. Como a Europa passava pela desconstrução do Welfare State e o contexto do Thatcherismo era fortemente liberal e flexível, a participação do setor privado foi estimulada no início da década de 1980 com a criação da London Docklands Development Corporation, a qual tinha a missão de implementar a regeneração da área. As críticas ao caso estão no fracasso imobiliário e no aumento dos desequilíbrios sociais (Branco-Teixeira, 1999).

Jordi Borja e Manuel Castells estão entre os pioneiros na sistematização teórica do planejamento estratégico, trazendo-o da realidade empresarial para as cidades. Os autores citados foram responsáveis, através do estabelecimento de consultoria internacional, pela difusão internacional desse modelo de planejamento - no caso, o modelo catalão, em particular na América Latina. Esse novo paradigma, o chamado "Planejamento Estratégico de Cidades", foi difundido pelo mundo a partir do "sucesso de Barcelona". Incansavelmente, fez-se propaganda das políticas urbanas que supostamente tinham a capacidade de resolver os problemas urbanos e tirar as cidades da crise. Tais políticas consistiam na união de esforços entre o setor público e privado para realizar um Projeto de Cidade e, assim, dar respostas aos objetivos da cidade de promover: "nova base econômica, infraestrutura urbana, qualidade de vida, integração social e governabilidade" (Castells \& Borja, 1996, p. 155). 


\section{O Planejamento Estratégico de Cidades: características e difusão}

A partir da década de 1990, chega à América Latina a ideia da cidade como um ator político e econômico, mas a "consolidação deste novo papel dependerá da possibilidade de estímulo de grandes projetos de cidade que contem com uma participação ativa dos principais agente públicos e privados e conquistem um amplo consenso público" (Castells \& Borja, 1996, p.154). O planejamento estratégico tem como um dos seus pilares a associação dos diversos atores urbanos através de parcerias público-privadas, pois se entendia que "a definição de um Projeto de Futuro só será eficaz se mobilizar, desde o seu momento inicial, os atores urbanos públicos e privados" (Castells \& Borja, 1996, p. 158). Entretanto, as chamadas "parcerias" entre as esferas pública e privada são criticadas pelo modo como muitas vezes são conduzidas, tendo em vista que:

este novo modelo de gestão público-privada tem provocado profundas e questionáveis mudanças na atuação dos governos municipais com relação às suas prioridades na alocação de recursos e compromissos na implementação de políticas, com tendências cada vez maiores a uma mercantilização da vida urbana (Sánchez, 1999, p. 118).

Segundo Harvey (1996, p. 53), o objetivo dessas parcerias é (apesar de não ser exclusivamente isso) "muito mais o investimento e o desenvolvimento econômico através de empreendimentos imobiliários pontuais e especulativos do que a melhoria das condições em um âmbito específico". Corroborando com esse ponto de vista e com um olhar sobre a realidade brasileira, Marcelo Lopes de Souza (2004, p. 55) afirma que:

Essas parcerias são estabelecidas visando à criação, execução e gestão de projetos em que, na maioria das vezes, o Estado (e, indiretamente, todos nós, pagadores de impostos) assume todos os riscos e custos, e o setor privado fica com a gestão e os benefícios (os lucros dos projetos). É como se o Estado "pusesse a mesa" para os empresários particulares, sob o argumento de que os empregos que serão criados e os recursos advindos do "aquecimento" da economia local justificariam isso - argumento esse que é, como muitos têm observado e mostrado, bem fraco. 
No Brasil, em meados da década de 1990, algumas cidades contrataram empresas de consultoria para realizar tais planos. O Rio de Janeiro se orgulhava de ser uma das primeiras a estar entre essas cidades a elaborarem seu plano. Embora bastante difundido, o modelo encontrou mais tarde os seus críticos, como revela o fragmento seguinte:

Não faltam aqueles que oferecem, a preços não módicos, fórmulas capazes de conduzir qualquer cidade ao pódio restrito das cidades globais. Os clientes, muitos prefeitos latino-americanos, buscavam salvar suas municipalidades da insolvência promovida pela crise fiscal, seguindo o modelo mais vendido do continente: Planejamento Estratégico, à la Barcelona (Maricato, 2001, p. 57).

Esse modelo, que ia se difundindo pelo planeta, defendia que "o governo local capaz de dar resposta aos atuais desafios urbanos e de construir um projeto de cidade, assim como de liderá-lo, tem de ser um governo promotor" (Castells \& Borja, 1996, p. 158). É o governo local que, para sair da crise, precisa agir como um ator privado, de modo a se promover no cenário competitivo no qual deve se enquadrar. A promoção da cidade deve ser feita para o exterior, a partir do seu interior, na medida em que

Cabe ainda ao governo local a promoção interna à cidade para dotar seus habitantes de "patriotismo cívico", de sentido de pertencimento, de vontade coletiva de participação e de confiança e crença no futuro da urbe. Esta promoção interna deve apoiar-se em obras e serviços visíveis, tanto os que têm caráter monumental e simbólico como os dirigidos a melhorar a qualidade dos espaços públicos e o bem-estar da população (Castells \& Borja, 1996, p. 160).

Dentro desse contexto, para promover a cidade para o exterior (no intuito de atrair "investidores e visitantes solventes" e dinamizar sua economia), é necessário gerar um consenso entre os cidadãos, os quais precisam confiar nos rumos da gestão. Para isso, vale construir grandes obras de caráter monumental, as quais têm a capacidade de gerar um sentimento de pertença, de patriotismo pela cidade, que é também o extermínio da crítica e do debate. Mesmo defendendo que o planejamento estratégico consolida a participação direta dos cidadãos, a partir do princípio de proximidade, os autores defensores do planejamento estratégico se contradizem. Ora, se os consultores trazem ideias, planos prontos e projetos acabados para que os cidadãos apenas os aprovem e, além disso, tenham suas "energias estimuladas" para a direção a qual se quer chegar, de que tipo de participação se está falando? 
Nesse mesmo sentido, já foram elaboradas inúmeras críticas ao modelo de planejamento estratégico adotado por cidades (ou melhor, em cidades) brasileiras. As críticas, em geral, concentram-se nas seguintes questões: 1) o modelo foi exportado de países europeus e dos Estados Unidos, sem se levar em consideração o contexto em que seria implementado; 2) os planos estratégicos não se preocupavam em verdade com a participação da população, antes, construíam na população os anseios do que se queria fazer, valendo-se do marketing urbano; 3) apesar de uma roupagem de abrangência de toda a cidade, grande parte das obras realizadas concentrou-se em área já enobrecidas, excluindo áreas que precisavam de investimentos e cuidados maiores; 4) na prática, os planos não mudaram muito as condições sociais dos mais necessitados, sendo, contudo, mais importantes para a dinamização da economia, favorecendo sobremaneira a elite local.

Dentre as críticas feitas a esse modelo de planejamento, destaca-se a obra intitulada "A cidade do pensamento único: desmanchando consensos", na qual Carlos Vainer, Otília Arantes e Ermínia Maricato fazem uma análise exaustiva sobre o planejamento estratégico, suas características e ferramentas. Carlos Vainer (2009) se utiliza de três analogias para explicar criticamente a leitura da cidade a partir da óptica dos defensores do planejamento estratégico de cidades: a cidade-mercadoria, a cidadeempresa e a cidade-pátria. A cidade-mercadoria remete à cidade como uma coisa, um objeto de luxo, o qual deve ser preenchido de atributos e embelezado para melhor ser vendido para aproveitamento de uma demanda solvável. De acordo com essa visão, alerta Vainer (2009, p. 83): “a cidade não é apenas uma mercadoria mas também, $e$ sobretudo, uma mercadoria de luxo, destinada a um grupo de elite de potenciais compradores: capital internacional, visitantes e usuários solváveis".

A cidade aparece também como uma empresa - daí o termo empresariamento ou empreendedorismo urbano usado por Harvey (1996) - que precisa agir estrategicamente coesa, para atingir os objetivos propostos. Vainer (2009) entende que a cidade-empresa causa a despolitização da cidade. O que ocorre não é apenas uma mudança gerencial, mas é a mudança no conceito de cidade, transformando-a em um sujeito econômico, cuja lógica de poder é usada para "legitimar a apropriação direta dos instrumentos de poder público por grupos empresariais privados" (p. 89). 
A ideia de cidade-empresa é acompanhada ainda da cidade como pátria, haja vista que no pragmatismo empresarial não há espaço para a política. Assim, "o plano estratégico supõe, exige, depende de que a cidade esteja unificada, toda, sem brechas, em torno ao projeto" (Vainer, 2009, p. 91). Para isso, os planos consideram de suma importância as condições de percepção da crise por parte dos citadinos, isto é, a consciência ou o sentimento de crise. Esse sentimento de crise, fugaz e passageiro é, então, transformado em patriotismo de cidade, mais duradouro e útil ao sentimento de sucesso planejado.

O patriotismo cívico é útil porque envolve os citadinos de forma com que se minem as chances de crítica ao modelo adotado, dando a impressão de que tudo vai bem e que se está no caminho certo. Carlos Vainer "participou" do processo de implementação do plano do Rio de Janeiro no início da década de 1990 como "conselheiro" e afirma ironicamente que "o plano é, pois, o mero enunciado da cidade que todos nós queremos e simplesmente ainda não sabíamos" (2009a, p.118).

Com a escolha do Brasil como país sede da Copa do Mundo de Futebol de 2014 e da Olimpíada de 2016, o planejamento estratégico reaparece com mais importância em cidades brasileiras. O caso mais ambicioso é o do Rio de Janeiro. O que mudou desde a experiência de planejamento acima relatada por Carlos Vainer? Há, de fato, participação popular nas tomadas de decisão sobre os eventos esportivos que acontecerão nos próximos anos?

A pretensão para o futuro da cidade não é pequena, pois o mais novo plano estratégico almeja que a cidade se torne, ao longo da próxima década, a "melhor cidade para se viver em todo hemisfério sul", recuperando ao mesmo tempo o dinamismo econômico e o protagonismo da cidade.

Introduzindo o plano estratégico, o prefeito do Rio, Carlos Paes (reeleito na última eleição de 2012), afirma que: 
A Prefeitura, através do seu Plano Estratégico, propõe um caminho para alcançarmos esse objetivo. E convida a refletir o que somos, o que pretendemos e - mais importante - como podemos juntos, poder público e cidadãos, redesenhar nosso futuro. Não se trata de apresentar à sociedade apenas um documento. Queremos construir juntos os fundamentos de uma nova realidade no Rio de Janeiro. A Prefeitura não pretende apenas orientar e tomar decisões sobre políticas públicas, quer também recuperar seu papel de pensar a cidade, influenciando investimentos e inspirando empresas e pessoas a pensar como agente de mudança (RIO, 2009, p. 5).

A democratização é uma tecla repetidamente tocada nos planos estratégicos. Isso não é novidade alguma. É preciso entender, contudo, que:

O discurso oficial que acompanha as novas políticas destaca, com ênfase, a vontade de envolver os cidadãos nos projetos de renovação urbana. De fato, criaram para a maioria da população um sentimento de orgulho e de "pertencimento" à cidade, mas esse sentimento gera, mais do que uma participação ativa, uma participação contemplativa da nova cidade. Com efeito, pensamos que a assistência ao espetáculo cria uma ilusão de participação (Sánchez, 1999, p.127).

Note-se que a cidade, em Castells \& Borja (1996), passa a ser vista como um ator. Ela se torna protagonista em si mesma, uma cidade-empresa coesa focada na sua melhor inserção no cenário de competição global entre cidades. Os interesses dos agentes, entretanto, escondem-se por trás do seu brilho e, a partir dos planos de embelezamento implementados, torna-se a "menina dos olhos" de todos os agentes, tanto públicos como privados, mas, principalmente dos turistas de luxo. Harvey (1996, p. 52) assinala, contudo, que "projetos pontuais desse tipo também costumam tornarse o foco da atenção pública e política a ponto de desviar a atenção e mesmo recursos de outros problemas mais importantes e que envolvem a região ou o território com um todo".

Na realidade, a venda da cidade como um espaço para atividades depende muito da criação de um imaginário urbano atraente. Lideranças da cidade podem considerar o desenvolvimento espetacular como "um líder de gastos" para atrair outras formas de desenvolvimento. Parte do que temos visto nas últimas duas décadas é a tentativa de construir um imaginário físico e social de cidades adequadas para estes propósitos competitivos (Harvey, 1996, p. 60). 
O marketing urbano, por sua vez, serve na construção da imagem atraente da cidade, da ideologia do "projeto de cidade" como única saída para enfrentar a "crise" por que passa a cidade. Nos planos, o que se dá maior visibilidade e interesse são justamente obras monumentais, na maioria das vezes concentradas nas áreas nobres das cidades. Para conseguir legitimar os planos, o marketing atrela-se às mídias locais e até internacionais propagandeando o desenvolvimento da cidade. Gera-se, assim, um consenso público a partir de um ator carismático. Esse personagem carismático (em geral o prefeito da cidade ou outra liderança política ou não) deve "unir a cidade" em torno de si, para que não se questione a importância dos planos no que concerne à minimização dos reais problemas enfrentados pela população. Ao contrário, pretendese que seja dada a legitimidade necessária à implementação desses planos. Nessa medida, na nova concepção de planejamento, a preocupação central do discurso dos consultores ligados à elaboração dos planos estratégicos é muito mais a de promover a cidade para o crescimento, do que propriamente administrá-la para o bem comum.

Desse modo, o discurso do empreendedorismo urbano é vendido por consultores como a panaceia para os problemas econômicos e sociais da cidade. Assim,

A ênfase no turismo, na produção e consumo de espetáculos, na promoção de eventos efêmeros numa dada localidade representam os remédios favoritos para economias urbanas moribundas. Investimentos urbanos desse tipo podem ser paliativos imediatos apesar de efêmeros aos problemas urbanos. Mas estes são, em geral, altamente especulativos (Harvey, 1996, p. 59).

Com "especulativos", Harvey pretende alertar para o caráter de imprecisão dos projetos urbanos. Apesar das contestações, há casos em que amplamente se julga haver um sucesso após investimentos empreendedores. No entanto, análises levam a crer que a preocupação de Harvey se justifica. Segundo Ferreira (2007), o caso de Londres pode ser considerado um estrondoso fracasso, tendo em vista que a forte atuação do Estado na compra de terras, na instalação de infraestruturas e no repasse por venda à iniciativa privada gerou um processo de gentrificação, no qual a população

\footnotetext{
2 Ao invés de crise é mais propício falar de sentimento de crise. Esse termo aparece em Borja \& Castells (1996), significando um elemento de auxílio para a consolidação dos projetos urbanos. A sensação de crise deve, segundo os autores, ser construída para gerar uma ação conjunta entre o poder local e os poderes econômicos no intuito de viabilizar as transformações da infraestrutura urbana.
} 
originária acabou por ser expulsa nos locais que receberam os investimentos. Pode-se acrescentar que:

\begin{abstract}
A gentrificação é, por definição, um processo de "filtragem social" da cidade. Vem desencadear um processo de recomposição social importante em bairros antigos das cidades, indiciando um processo que opera no mercado de habitação, de forma mais vincada e concreta nas habitações em estado de degradação dos bairros tradicionalmente populares. Correspondendo à recomposição (e substituição) social desses espaços - tradicionalmente da classe operária/ popular - e à sua transformação em bairros de classes média, média-alta - não se pode deixar de referir, por conhecimento deste processo de "substituição social", o reforço da segregação sócio-espacial, que na sua sequência parece aprofundar a divisão social do espaço urbano (Mendes, 2010, p. 23).
\end{abstract}

Diante das consequências sociais, como a gentrificação e de tantos insucessos, cabe, então, perguntar: a escolha do modelo de empreendedorismo urbano pelas cidades brasileiras como planejamento e gestão pode ocorrer sem considerar o seu contexto histórico, suas variáveis, suas demandas e o querer da população? Pode uma fórmula de planejamento criada em condições bastante distintas ser a solução para os problemas urbanos das cidades brasileiras? Para pensar essas questões é necessário discutir, no próximo item, o contexto em que se deu a chegada do planejamento estratégico nas cidades brasileiras. Antes de tudo, pode-se adiantar que o que de fato foi vendida nas cidades brasileiras foi a ideia, o discurso do planejamento estratégico, e não o modelo implementado conforme o caso catalão. De qualquer forma, o problema todo parece estar ligado, muito mais do que aos planos estratégicos, às elites locais que continuam dando uma nova roupagem à cidade como máquina de crescimento, perpetuando às formas de reprodução do status quo.

\title{
3. O empreendedorismo urbano no Brasil
}

Quando o empreendedorismo chegou ao Brasil o contexto político nacional era o das transformações causadas pela Constituição de 1988. Com a falência desses modelos globais de planejamento, somada ao fim da ditadura militar, descentralização política, "redemocratização" e efervescência de movimentos sociais, formou-se uma conjuntura de "crítica radical do planejamento urbano e, ao mesmo tempo, reforçou a 
crença de que somente as lutas urbanas seriam capazes de influenciar decisivamente os destinos da cidade" (Ribeiro \& Cardoso, 2003, p. 107).

É nesse contexto que vai se gestando um processo de luta pela Reforma Urbana, mas "diante da mobilização popular dos anos 80, a facção da classe dominante com interesses vinculados ao espaço urbano - especialmente o setor imobiliário - reage exatamente como a ditadura militar de 64: com Plano Diretor" (Villaça, 2000, p.13). A obrigatoriedade do Plano Diretor é introduzida no artigo 182 da Constituição Federal de 1988, mas é preciso dizer que esse novo Plano Diretor tem uma natureza diferente daquele da época ditatorial, pois agora se trata do plano diretor participativo, a ser regulado pelo que viria a ser, posteriormente, a lei federal intitulada Estatuto da Cidade, o aporte legal para a transformação na maneira de se planejar o espaço urbano, com uma maior preocupação social.

Os planos diretores, exigidos pela lei e incentivados pelo Ministério das Cidades, não são um fato novo, pois já apareciam na estrutura de planejamento urbano de cidades brasileiras. Como afirmam Junior \& Montandon (2011, p. 27), "a elaboração de Planos Diretores como instrumentos de planejamento do uso do solo urbano não é recente; aparece na história do urbanismo brasileiro desde a década de 1930, quando foi elaborado o Plano Agache no Rio de Janeiro". Segundo Ultramari \& Rezende (2008, p. 724):

Já nos anos 70, o então Ministério do Interior [MINTER] promovia a elaboração desses Planos, por meio de uma linha de crédito específica do então Banco Nacional de Habitação [BNH] e implementada sob a coordenação do extinto Serviço Federal de Habitação e Urbanismo [SERFHAU]. Os Planos Diretores Municipais realizados naquela década podem ser caracterizados pelo tripé seguinte: 1. pela valorização do ordenamento físico-territorial, por meio da elaboração de legislações urbanas básicas, tais como leis de uso do solo; 2 . Pela limitação de tratarem exclusivamente a área urbana do município; e 3 . pelo seu caráter tecnocrático, sem o envolvimento da população ou mesmo das equipes das prefeituras locais.

Com a Constituição brasileira de 1988 e os processos políticos subsequentes a ela, buscou-se dar uma nova roupagem ao papel dos planos diretores, a partir da atuação dos movimentos sociais organizados, bem como de planejadores mobilizados. Emergia a ideia de planejamento politizado, a qual buscava reduzir as desigualdades sociais 
presentes nas cidades (Ribeiro \& Cardoso, 2003). O planejamento politizado pretendia também ultrapassar o caráter tecnocrático dos planos diretores do passado, introduzindo novos instrumentos de gestão nos planos diretores para regular o crescimento urbano, conter a especulação imobiliária, dar transparência à gestão da cidade e melhores condições de participação da sociedade e de controle dos orçamentos públicos.

Embora houvesse certa esperança que os processos jurídicos causassem avanços, havia também a descrença no planejamento urbano. A vertente mais crítica que abrange parcela da esquerda pode ser resumida, segundo Souza (2004, p. 20), com a seguinte máxima: "O Estado capitalista está a serviço das classes dominantes; o planejamento urbano é levado a efeito pelo Estado capitalista; logo, o planejamento urbano é feito para beneficiar as classes dominantes". Nessa visão o planejamento se constitui intrinsecamente como conservador. Contudo, o próprio Souza (2004, p. 20) explica que essa perspectiva é reducionista por não considerar uma possível ocupação do Estado por forças políticas comprometidas com a mudança, além de que os setores da sociedade civil têm a possibilidade de conceber propostas e lutar para colocá-las em prática.

Se, por um lado, não faltava desconfiança da esquerda ao planejamento urbano, a ala conservadora também criticava o planejamento, afirmando ser a gestão algo mais flexível do que a rigidez estatal e, por isso, dever-se-ia substituir o planejamento pela gestão. De todas as formas, o planejamento foi perdendo, nessa medida, a sua legitimidade. Segundo Souza (2004, p. 22), a emergência dos símbolos Ronald Reagan nos EUA e Margaret Thatcher no Reino Unido e a falência do Keynesianismo contribuíram para que "se questionasse, em nível local, a legitimidade do Estado como regulador do uso do solo urbano e, com isso, se enfraquecesse e se buscasse deslegitimizar o planejamento". O autor afirma ainda que o planejamento "mercadófilo", isto é, amigo do mercado, foi tomando o lugar do planejamento regulador e dando uma nova roupagem conservadora ao planejamento urbano. Conforme Souza (2004, p. 53) explicita, 
Nos anos 1980 e 1990 assiste-se a um enfraquecimento do antigo planejamento urbano regulatório, baseado em normas, leis e ações criadas pelo estado para regular e normatizar os diferentes usos dos espaços da cidade. Em meio à onda neoliberal emerge um planejamento "mercadófilo". O que conta nesse tipo de planejamento é a capacidade da cidade de atrair investimentos: do oferecimento generoso de infraestrutura para megaempreendimentos empresariais até incentivos ficais, passando pelo marketing urbano. Propala-se a idéia de que esse esforço do contribuinte vale a pena, pois gera empregos e aquece a economia local.

Como já foi dito, tais planos foram ganhando espaço nas cidades brasileiras somente no final da década de 1990 e início do século XXI, com anos de atraso, apesar dos avanços gestados no movimento social pela reforma urbana desde a década de 1980, a partir de uma base social e um debate a nível nacional (Sànchez, 1999). Os encantos do novo planejamento "ofuscaram" a construção do movimento pela reforma urbana e conseguiram a adesão dos prefeitos das municipalidades, os quais elaboravam com negligência os planos diretores, enquanto que os planos estratégicos eram vistos como a panacéia para os desafios urbanos. Mesmo assim, o movimento social já conseguira paulatinos avanços na política urbana, a qual teve como alavanca a Constituição de $1988^{3}$, com novos conceitos de função social da cidade e função social da propriedade, além de novos instrumentos de gestão urbana, tais como o plano diretor participativo, que se tornou obrigatório apenas para as cidades com mais de 20.000 habitantes.

A Constituição de 1988 foi um marco para a política urbana brasileira. Passou-se a considerar a importância das autoridades locais no sentido de desenvolver as funções sociais da cidade e o bem-estar dos cidadãos, por meio do uso de diversos instrumentos que surgiram com o advento da referida constituinte. Para Edesio Fernandes (1998, p. 221), a Constituição também foi importante no sentido de reconhecer o caráter político que envolve as decisões sobre as questões urbanas, tendo em vista que, "se o Estado foi confirmado como o promotor preferencial do

\footnotetext{
${ }^{3}$ Há quem prefira ver os avanços da política urbana da Constituição de 1988 muito mais como uma resposta de resistência das elites às propostas populares e não propriamente resultado do Movimento Nacional de Reforma Urbana. Acredita-se aqui, contudo, que os poucos avanços não seriam possíveis sem tal movimento, embora não se tenha conseguido ainda ver todas as demandas atendidas.
} 
processo de crescimento urbano, também foi reconhecido um novo direito social - o direito ao planejamento urbano".

O Estatuto da Cidade - Lei 10.257 de julho de 2001 - regulamenta o capítulo "política urbana", buscando "virar a página de um tempo de clientelismo, troca de favores e promiscuidade entre a elite das cidades e os gestores urbanos" (Alfonsin, 2003, p. 96). O Estatuto da Cidade trouxe à tona diversos instrumentos, sendo alguns desses de responsabilidade dos municípios, na elaboração do Plano Diretor. Entretanto, mesmo com os avanços nacionais de luta pela reforma urbana e de remodelação política dos planos diretores:

\begin{abstract}
A ideia de plano para a cidade é substituída pela de projeto, e as preocupações finalísticas são abandonadas em favor de uma concepção instrumental na intervenção, através da qual busca-se dotar a cidade de elementos que melhor a adaptem aos requerimentos e necessidades da flexibilidade e da competitividade. É por esta razão que presenciamos a volta ao monumentalismo e ao embelezamento como padrão de intervenção urbanística (Ribeiro, 2003, p. 19).
\end{abstract}

Mesmo que a aprovação do Estatuto da Cidade tenha trazido de volta a discussão sobre os planos diretores e até a sua obrigatoriedade, cidades brasileiras ainda permanecem influenciadas pela lógica do planejamento estratégico, com a priorização de grandes investimentos públicos para as áreas de maior dinamismo da cidade, ou seja, para as áreas nobres, os bairros de status, no intuito tornar a cidade mais atrativa. A literatura traz exemplos concretos de que isso ocorre em cidades como Curitiba, Rio de Janeiro, Niterói, São Paulo, dentre outras. Outras cidades de menor porte, mesmo sem ter tanto investimentos no discurso da cidade global, apresentam fragmentos desse modelo de planejamento. Assim, a meta das cidades ainda é crescer (a sua economia) e melhorar sua condição de competitividade através da construção de elementos ou atributos para serem vendidos para visitantes e investidores, mesmo que não haja a formulação de planos tais quais os elaborados seguindo o modelo do planejamento estratégico de cidades. 


\section{Empreendedorismo urbano periférico ou planejamento estratégico sem plano.}

O planejamento estratégico não chega às cidades brasileiras da mesma maneira tal qual foi concebido e implementado nos exemplos de "sucesso" pelo mundo afora. Destarte, qualquer análise a respeito desse tema precisa levar em conta o contexto no qual os planos estratégicos foram sendo pensados e conduzidos nas cidades brasileiras. Assim, é inerente a tal análise o conhecimento da estrutura política, econômica, social e cultural. Deve-se considerar o contexto histórico e temas ligados a esse modelo de planejamento, como as parcerias entre o setor público e o privado; a dinâmica imobiliária; as condições gerais de participação e cultura de envolvimento político, dentre outros.

Nessa medida, uma primeira questão é aqui levantada. Castells \& Borja (1996, p. 153) consideram que, para que uma economia urbana tenha sucesso, mais importante do que "as posições adquiridas no passado, o capital acumulado, as riquezas naturais ou a situação geográfica" é a "velocidade da informação sobre os mercados internacionais", "a flexibilidade das estruturas produtivas e comerciais", bem como a "capacidade de inserir-se em redes". Nesse ponto os autores dão o exemplo do rápido crescimento das cidades asiáticas. Embora verdadeiras em parte, essas afirmações desconsideram os "altos custos sociais" (os quais os autores mesmo reconhecem), que são fatores cruciais que impulsionaram a ascensão econômica daquelas cidades. Nesse sentido, as condições históricas favoráveis são inegavelmente importantes para o crescimento das cidades. É certo que, como afirma Peter Hall, “a 'morte das distâncias' trabalha em favor das cidades inovadoras, criativas e ambiciosas, permitindo cidades em desenvolvimento cumprirem os requerimentos locacionais do mercado global" (Hall, 2000, p. 54). Contudo, como mostra Rose Compans (1999, p. 104), por mais que haja uma desconcentração da indústria para várias partes do mundo, as grandes firmas do mundo atual continuam sendo americanas, inglesas, japonesas, alemãs etc., no máximo, são binacionais. Dessa forma, a autora explica que são mínimas as chances 
das cidades do "Terceiro Mundo" se integrarem com os fluxos econômicos globais, de outra forma que não seja para fornecimento de mão-de-obra mal remunerada e precária. Assim sendo, o quadro dessas cidades se assemelha muito mais com a produção industrial do que com o "terciário avançado", caracterizado pelas estruturas flexíveis e em redes. Com isso, qualquer estudo acerca do envolvimento de uma cidade nessa competição global entre cidades, precisa levar em conta os problemas sociais causados ou acentuados com a busca da inserção no cenário global, mesmo quando se fala de um empreendedorismo urbano em uma escala menor.

Há, nessa medida, uma hierarquia entre as cidades, isto é, uma escala de “importância” dessas cidades. Diversos pesquisadores têm buscado modelos para medir a hierarquia entre as cidades, onde os rankings trazem, dependendo da metodologia, as cidades que estão na ponta do processo. A maioria dos pesquisadores, contudo, negligenciou a análise das cidades "não-globais", isto é, das cidades que são excluídas do modelo de desenvolvimento flexível e competitivo ou que são inclusas de forma periférica, estando à margem desse desenvolvimento. É importante entender que mesmo não estando dentro desse ranking, algumas das cidades "não-globais" têm sido influenciadas pela lógica do empreendedorismo e da competição que caracterizam as cidades globais. Estas últimas são tidas como modelos, a serem imitados, especialmente os casos de um sucesso "repentino". Cidades podem chegar de súbito aos primeiros lugares do ranking de fluxos turísticos, como Kuala Lumpur, Taipei, Shanghai, Dubai e Abu Dhabi. Os investimentos necessários para isso, contudo, são enormes, pois se dão por meio da construção de luxuosos hotéis e centros de lazer, além de uma "europeização" com direito à abertura de filiais dos museus Louvre e Guggenheim. Em que medida esses investimentos são possíveis nas cidades brasileiras?

Na linha do que defende Compans (1999), nessa medida, as cidades do "Terceiro Mundo" que se aventuram nessa perspectiva dos grandes investimentos, quase sempre apresentam uma mão de obra barata. Segundo Mike Davis (2006), a resposta às inquietações dos trabalhadores que reclamam das condições do trabalho pode chegar até à expulsão ou prisão em Dubai. Enquanto isso, a cidade vende uma imagem de paraíso e consegue escapar da pobreza graças ao fato de ter se tornado um eixo de 
comércio, finanças e lazer. Apesar de todos os investimentos, Dubai é um exemplo de que a inserção dos países do "Terceiro Mundo" nas redes de fluxos globais passa pelo fornecimento de mão-de-obra mal remunerada e precária.

Como observou Hall (2000, p. 53), há dois tipos de mercados urbanos. O primeiro está conectado com o mercado externo, com intercâmbio de bens comercializáveis; o segundo é o que fornece bens locais. Ora, até mesmo nas cidades maiores e mais globalizadas, a maioria da produção e consumo é local. Segundo o autor, enquanto que as cidades centrais aproveitam altas rendas e acumulação de riquezas, as cidades periféricas são deixadas para trás. Com isso, "meros $28 \%$ de toda a população mundial recebe não menos que $91.5 \%$ de todos os investimentos estrangeiros". (Hall, 2000, p. $54)$.

Castells \& Borja (1996, p. 157) acreditaram ainda que, com a abertura econômica na América Latina, os interesses privados reconheceriam a necessidade de se mobilizar como agentes econômicos para contar com uma cidade mais competitiva, estabelecendo "objetivos e ações de caráter coletivo e compatíveis com o governo local". Contudo, apesar dos agentes privados "reconhecerem" a necessidade de a cidade ser competitiva, comumente espera que o setor público faça os investimentos de risco e privatize os setores estratégicos. A participação do setor privado nas chamadas "parcerias" não se deve, assim, ao reconhecimento da importância de uma cidade competitiva, antes, trata-se de investimentos seguros e com grandes concessões para o setor privado, com isenções de impostos e "privatização" do público, mesmo que em caráter temporário.

Outro fator chave de diferenciação do contexto do Brasil e da América Latina em geral é o pouquíssimo envolvimento e participação da população nas tomadas de decisão nos rumos das gestões e do planejamento das cidades. Milton Santos (2007) chegou a afirmar que "o espaço em que vivemos é, na realidade, um espaço sem cidadãos" (p. 65), tendo em vista que "sem a possibilidade de cobrar dos eleitos realizações prometidas, a figura do cidadão verdadeiro é inexistente" (p. 159). Adiante, o autor ainda questiona: "A informação para quê? A informação para quem?" quando discute que na era informacional "o estoque de informações, inclusive as que concernem a 
cada indivíduo em particular, é manipulado por poucas pessoas, que podem fazer dela um uso indevido" (Santos, 2007, p. 155).

Não se quer dizer com isso que fora do Brasil a cidadania e a participação ocorram sem problemas. Ao contrário, sobre o caso de Barcelona vê-se que o projeto de cidade e a construção de uma ideologia de coletividade são fortes a tal ponto que "qualquer atitude crítica é tomada como não gostar da cidade. Por isso, há uma grande dificuldade em exercer a crítica" em Barcelona (Naya, 1998 apud Sánchez, 2010, p. 413). Mesmo com essa dificuldade de exercer a crítica em Barcelona, Ferreira (2007, p. 131) afirma que "a resistência local é significativamente forte, acusando o modelo pelo seu liberalismo absoluto e seu poder de segregar as populações mais pobres". No entanto, o que agrava o caso brasileiro é a concentração de renda ${ }^{4}$, o quadro de pobreza e a crise social por que passam as cidades brasileiras em relação a uma situação bem mais confortável em Barcelona ${ }^{5}$. A respeito dessa questão, Ferreira (2007, p. 131) observa que:

A realidade econômica das cidades do Norte, a magnitude de capital investido em políticas públicas e o grau bem mais aceitável de distribuição de renda e equilíbrio social - construídos em décadas de políticas de bem-estar social, fazem com que os efeitos perversos do liberalismo econômico e urbanístico sejam bem menos sentidos.

O certo é que muitas cidades, "ricas" ou "pobres", no atual período, visam construir sua imagem no cenário internacional através do marketing urbano, para melhor venderem-se para os investidores e turistas solváveis. Em se tratando de imagem, nada melhor do que a arquitetura. Como nem todas as cidades podem ter grandes projetos com consultorias ou mesmo associações de grandes obras com nomes de arquitetos de grife, mas acreditam no "mito da cidade-global" - ver Ferreira (2007) -, acabam tentando imitar as tendências de se produzir a cidade. Não se trata apenas de projetar-se no cenário internacional, apesar desse ser o sonho, mas trata-se de aderir

\footnotetext{
${ }^{4}$ Segundo o documento da ONU “Estado Mundial das Cidades 2008/2009” as cidades brasileiras apresentam a maior disparidade de distribuição de renda do mundo.

${ }^{5}$ Obviamente não é desprezível a crise econômica e social que atinge a Espanha e a Europa como um todo, sobretudo com os conflitos por causa do desemprego.

${ }^{6}$ Estudos vêm pondo à prova a tendência a dualização e polarização enfatizando a importância das classes médias na estruturação social das metrópoles brasileiras, nas quais ocorre a coexistências de várias situações sociais e urbanas. Ver Clementino \& Pessoa (2010, p. 1) e Preteceille \& Ribeiro (1999, p. 144).
} 
ao planejamento estratégico, mesmo que seja para melhorar as condições locais de competição intrarregional. Os maiores competidores estão, no caso das cidades de médio e pequeno porte, por perto.

Buscando prever e entender as demandas da agenda das cidades no contexto do início do século XXI, Peter Hall já alertava uma tendência de imitação, pois cada vez mais será dado lugar, nas cidades globais, à competição "através do processo de imitação e adaptação". Entretanto, segundo o autor, muitas cidades ficarão de fora da linha de frente do progresso tecnológico e de inovação, limitando-se na "concentração da imitação e da produção e serviços simples" (Hall, 2000, p. 62). As cidades que não estão na ponta do processo de fluxos globais, assim, incorporam o empreendedorismo apenas como uma roupagem, isto é, não conseguem desempenhar as funções de uma cidade global ou não participam da dinâmica global de forma preponderante. $\mathrm{Na}$ verdade, apenas vão imitando as tendências e adaptando as suas realidades.

Não é que agora cidades brasileiras possuirão a arquitetura de Bilbao, a fama de Barcelona e/ou o fluxo turístico de Londres ou Paris, mas as ações gestadas são imitações e adaptações de modelos de fora, e não resultados de um planejamento a partir das demandas locais, um verdadeiro desenvolvimento endógeno. Não se tratam somente de cidades brasileiras que trouxeram empresas de consultorias de fora e investiram no planejamento estratégico. Igualmente, encontram-se cidades de menor porte, as quais se deixaram influenciar pela "moda" do planejamento estratégico desde meados da década de 1990. Tais cidades adotaram modelos parciais de desenvolvimento dentro da lógica de competição, de maneira que não podem parar de investir na construção de atributos ou elementos que a tornem mais atrativa.

Em geral, as cidades brasileiras se voltaram para as mesmas tendências e atributos: a revitalização dos centros históricos, o embelezamento de canteiros e fachadas, o investimento em aeroportos, a construção de hotéis de luxo, centros de convenções, museus, monumentos e outras obras associadas à marca de arquitetos de renome, a organização de feiras e eventos, além do marketing urbano, instrumento capaz de dar ênfase aos atributos da cidade e promover a sua "venda". As cidades vão assumindo as características físicas e a maneira de produzir a cidade seguindo a mesma lógica do planejamento estratégico, mesmo que não elaborem os planos estratégicos ou que os 
planos elaborados não correspondam às ações implementadas. É uma forma de "planejamento estratégico sem plano". Aí, o que se está chamando de "planejamento estratégico" não tem o sentido de planejamento tradicional, pelo qual se preveem e antecipam as problemáticas. Antes, fala-se de planejamento estratégico como uma fórmula vendida e difundida a partir dos casos de sucesso, que supostamente é capaz de tirar as cidades das crises em que estejam inseridas. Em outras palavras: como o planejamento estratégico se constitui muito mais como um modelo de gestão do que um planejamento propriamente dito, ele pode ser conduzido sem planos, ou seja, apenas com os investimentos à luz da lógica da competitividade dos interesses privados.

Quando se fala de "planejamento estratégico sem plano" - o que em si é uma contradição -, quer dizer que os elementos do planejamento estratégico são adotados pela cidade, mesmo que não tenha planos. É apenas a tendência, a moda, a maneira de se produzir a cidade. É o que também se denomina, aqui, de "empreendedorismo urbano periférico ou incompleto", pois essas cidades entram em cena para se tornarem protagonistas, mas não passam de coadjuvantes diante das adversárias que estão na frente. Podem, obviamente, conseguir melhorar seu desempenho local e regional, mas não ocuparão os primeiros lugares do ranking das cidades globais, como promete muitas vezes o discurso do planejamento estratégico.

Já não se constrói a cidade a partir da lógica de funcionalidade típica do período modernista, mas a partir do viés da cidade contemporânea que atribui mais importância às formas estéticas e aos valores simbólicos do que propriamente às funções que as formas exercem. Assumindo esse modelo, a cidade entra no mercado da competição, o qual é insaciável, pois nele as cidades buscam sempre se renovar e melhorar sua posição. Não que as formas das cidades que estão dentro dessa lógica aqui chamada de empreendedorismo incompleto possam ser comparadas às obras retorcidas, ditas pós-modernas de cidades como Bilbao, mas já consegue observar obras pontuais que seguem esse modelo de arquitetura.

Não qualquer tipo de arquitetura, antes, arquitetura de grife, de ponta, de marca. Nesse contexto, busca-se associar a cidade à obra arquitetônica e ao arquiteto (ou às grandes empresas de arquitetura), no intuito de se tornarem mais atrativas ou até 
uma "cidade-global". Algumas dessas "cidades globais" apresentam uma verdadeira coleção de grifes. Um exemplo é Bilbao, que, com suas 25 transformações, reúne nomes, como os de Frank Gehry, Norman Foster, Santiago Calatrava, César Pelli, dentre tantos os que assinam os seus monumentais arranha-céus, shoppings, museus, e outros grandes projetos urbanos (Bonates, 2009).

Em contraposição, esse movimento de arrancada, em busca do topo da tecnologia e inovação através da arquitetura, acaba causando desigualdades entre as cidades, tendo em vista que nem todas as cidades podem se inserir nesse processo (ou se inserem com um papel secundário). Na medida em que cidades ostentam o espetáculo da arquitetura, ofuscam a pobreza que se encontra em outras cidades ou mesmo - o que é pior -, em outras áreas da mesma cidade que não recebem tantos investimentos em infraestrutura e atenção por parte dos gestores públicos.

Nesse processo de imitação, cidades vão construindo atributos no intuito de se tornarem diferenciadas e mais atrativas, mas muitas vezes tornam-se iguais. A "pelourinização" dos centros históricos das cidades brasileiras, para usar um termo do arquiteto Marcelo Ferraz, é um típico exemplo disso. O que se acredita hoje ser riqueza sociocultural apresenta-se, muitas vezes, como a invenção de realidades que nunca existiram. A esse respeito, Valença (2010a, p. 8) afirma que:

(...) na era da reprodutibilidade técnica da obra de arte - em que tudo se reproduz em série, ou seja, não mais existe uma peça original única, mas vários originais -, todas as principais cidades desenvolvem seus "centros", renovam, inventam e reinventam seus "patrimônios" (nem sempre históricos, mas que se tornam simulacros da história). As cidades, em vista da crescente competição internacional, são, nesse aspecto, todas 'iguais'.

Aí mora uma contradição: enquanto as cidades buscam o diferencial e a inovação que Ihes garanta auferir rendas de monopólio, acabam se tornando iguais. Arantes (2008, p. 179) percebeu essa contradição quando afirmou que "o sucesso estrondoso de algumas obras e seus arquitetos, contudo, acaba estimulando a repetição das mesmas fórmulas projetuais, reduzindo a cada 'duplicação' de volumetrias similares sua competência em gerar rendas de exclusividade".

A renda de monopólio surge, como afirma Harvey (2002), quando atores sociais podem realizar fluxos de renda reforçados por um tempo mais prolongado em virtude 
do controle da exclusividade sobre algum item. Para Ribeiro (1997, p. 67), "o preço do monopólio nasce quando tem-se um bem não-reprodutível ou parcialmente reprodutível". Ainda com relação à renda de monopólio, Gonzales (1985, p. 99) afirma que "tal situação se verifica quando uma determinada área apresenta condições excepcionais de produção de mercadorias raras, em quantidades limitadas no mercado e com preços maiores que o valor de sua produção". Em suma, renda de monopólio refere-se à raridade de determinada mercadoria.

O museu Guggenheim é um caso que merece destaque, pois, "ao ser divulgado pelos canais midiáticos como ápice da produção arquitetônica recente, gerou fabulosas rendas de monopólio para os diversos agentes envolvidos" (Arantes, 2008, p. 188). Entretanto, é necessário notar que o Guggenheim não é só um museu, mas uma rede de museus, os quais podem ser encontrados não só em Bilbao, mas em Veneza, em Berlim e dois em Nova lorque. Além disso, há outras cidades que querem trazer ao seu tecido urbano a marca Guggenheim, tais como o Rio de Janeiro, Abu Dhabi, Taichung e Vilnius (Bonates, 2009). Isso demonstra o que Arantes (2008, p. 179) chamou de limite comercial da arquitetura de marca, que é obrigada "a adotar soluções inusitadas $e$ sempre mais chamativas: se diversas cidades almejarem uma obra de Frank Gehry, por exemplo, perderão progressivamente a capacidade de capturar riquezas por meio de projetos desse tipo". Harvey (1996, p. 59), nessa mesma linha, faz a seguinte reflexão:
Muitas das inovações e investimentos destinados a tornar determinadas cidades mais atraentes como centros culturais e de consumo rapidamente foram imitados em outros lugares, tornando, assim, efêmera toda vantagem competitiva dentro de uma rede de cidades. Quantos centros de convenções exitosos, quantos estádios de esporte, disneyworlds, portos e shopping centers espetaculares podem existir?

Dessa questão elaborada por Harvey pode-se pensar outra questão: se os limites comerciais dos investimentos na arquitetura de marca são notórios, o que dizer das cidades que já têm seus projetos urbanos resultantes da imitação de outras localidades? Parece óbvio que isso pode acabar inviabilizando rendas de monopólio. Desse modo, enquanto que algumas cidades buscam acirradamente tornarem-se inovadoras para atingir criativamente o topo na competição entre cidades, outras se inserem no processo, aproveitando a onda de imitação das cidades globais. 
Ao imitar essa tendência, a maioria das cidades o faz mesmo que não haja um planejamento adequado. Não que o planejamento urbano seja a panacéia dos problemas da cidade. Ao contrário, como afirma Villaça, (2000, p. 4), "a verdade é que a existência ou não de infraestrutura e de equipamentos sociais nada tem a ver com 'planos' ou 'crescimento ordenado'". O autor vai além da ideia de ordenamento quando explica que:

A crença de que com ordem, se consegue resolver os problemas urbanos, suaviza e mesmo oculta a verdade que são necessários investimentos e não apenas "planos" para atacar os problemas urbanos. Claro que os investimentos com "planos" são melhores, mais rentáveis, do que os investimentos "sem planos"... mas os "planos" estão longe de ser suficientes. Entretanto, a ideologia do "crescimento ordenado" confere a eles um poder que eles, por si só não têm e esconde nossa realidade urbana (Villaça, 2000, p. 2).

Villaça sugere a importância de se pensar os planos e o planejamento urbano a partir da ótica dos investimentos para sanar com os problemas urbanos. Sem tais investimentos, os problemas tenderão a aumentar, especialmente em situações nas quais a concentração de renda aumenta cada vez mais. Seria plausível, então, pensar uma renovação do quadro urbano atual através de uma visão revolucionária?

Para Lefebvre (2001, p. 112), "em si mesma reformista, a estratégia de renovação urbana se torna 'necessariamente' revolucionária, não pela força das coisas mas contra as coisas estabelecidas". Entretanto, Harvey (2002) argumenta que as transformações urbanas tão necessárias hoje não devem esperar a revolução socialista ou algo do tipo. Para o autor, essa necessidade de esperar a revolução socialista é um mito a ser combatido. Na verdade, para ele, as transformações urbanas devem acontecer em um processo contínuo de mudança socioambiental.

Esse processo contínuo de mudança socioambiental nas cidades passa pelo empreendedorismo urbano? De qualquer modo, o que se sabe é que as "abordagens empreendedoras, ações para melhorar a qualidade dos espaços públicos não necessariamente melhoram as condições sociais existentes na cidade e podem até fazer mais mal do que bem em termos de justiça social" (Valença, 2010b, p. 67). 


\section{Referências}

Alday, H. (2000). O Planejamento Estratégico dentro do conceito de Administração Estratégica. FAE, Curitiba, v.3, n.2, p.9-16, maio/ago.

Alfonsin, B. (2003). O significado do Estatuto da Cidade para a Regularização Fundiária no Brasil In Ribeiro, L. \& Cardoso, A. (Organizadores). Reforma Urbana e Gestão Democrática: promessas e desafios do Estatuto da Cidade. Rio de Janeiro: Revan: FASE. Arantes, P. (2008). O grau zero da arquitetura na era financeira. Novos Estudos. CEBRAP.

Bonates, M. (2009). "El Guggenheim y mucho más" - urbanismo monumental e arquitetura de grife em Bilbao. Revista do Programa de Pós-Graduação em Arquitetura e Urbanismo. FAUUSP [online]. n. 26, pp. 62-90. ISSN 1518-9554.

Branco-Teixeira, L. (1999). O. Reconversão de áreas urbanas em frentes de água In: $\underline{A}$ Cidade da EXPO'98, ed. Matias Ferreira, V. e Indovina, Francesco. Lisboa, Portugal: Bizâncio.

Castells, M. \& Borja, J. (1996). As Cidades como Atores Políticos. Novos Estudos, CEBRAP, n.45, São Paulo.

Clementino, M. \& Pessoa, Z. (2010). Tipologia socioespacial numa metrópole em formação: a RMNatal In: Natal: uma metrópole em formação. Clementino, M. \& Pessoa, Z. (Orgs). FAPERN.

Compans, R. (1999). O paradigma das global cities nas estratégias de desenvolvimento local. Revista Brasileira de Estudos Urbanos e Regionais, no 1, Campinas: ANPUR, p. 91 $-114$.

Corrêa, R. (2011). Sobre agentes sociais, escala e produção do espaço: um texto para discussão In: Carlos, A., Souza, M. \& Sposito, M. (Orgs.). A Produção do Espaço Urbano: agentes e processos, escalas e desafios. São Paulo: Editora Contexto. 
Davis, M. (2006) Fear and Money in Dubai. New Left Review. Disponível em: http://newleftreview.org/?page=article\&view=2635. Acessado em: 05/03/2012.

Fernandes, E. (1998). Direito do urbanismo: entre a "cidade legal" e a "cidade ilegal" in Fernandes, E. (Org.). O direito urbanístico. Belo Horizonte: Del Rey

Ferreira, J. (2007). O mito da cidade-global: o papel da ideologia na produção do espaço urbano. Petrópolis, RJ: Vozes; São Paulo, SP: Editora Unesp; Salvador, BA: Anpur, (capítulo 4).

Gonzales, S. (1985). A Renda do Solo Urbano: Hipóteses de explicação de seu papel na evolução das cidades. In Farret, R; Gonzales, S.; Holanda, F.; Kohlsdorf, M. O Espaço da Cidade - Contribuição à análise urbana. São Paulo: Projeto.

Hall, P. \& Pfeiffer, U. (2000). Urban Future 21, a global agenda for Twenty-first Century Cities. London: F\&N Spon. Chapter II

Harvey, D. (1996). Do gerenciamento ao empresariamento: a transformação da administração urbana no capitalismo tardio In: Espaço \& Debates - Revista de Estudos Regionais e Urbanos. Ano XVI, n. 39, Cidades: Estratégias Gerenciais. São Paulo: NERU/CNPq/FINEP.

Harvey, D. (2002). Mundos urbanos possíveis. Novos Estudos, CEBRAP, n.63, 3-8.

Harvey, D. (2010). Condição pós-moderna: Uma pesquisa sobre as origens da mudança cultural. Edições Loyola, São Paulo.

Junior, O. \& Montandon, D. (2011). Síntese, desafios e recomendações In: Junior, Orlando Alves dos Santos \& Montandon, Daniel Todtmann (Orgs). Os Planos Diretores Municipais Pós-Estatuto da Cidade: balanço crítico e perspectivas. Rio de Janeiro: Letra Capital: Observatório das Cidades: IPPUR/UFRJ.

Lefebvre, H. (2001). O direito à cidade. São Paulo: Centauro.

Lima Junior, P. (2003). Uma estratégia chamada "planejamento estratégico": deslocamentos espaciais e atribuições de sentido na teoria do planejamento urbano. Tese de Doutoradamento. Rio de Janeiro: UFRJ. 
Lopes, R. (1998). A Cidade Intencional: o planejamento estratégico de cidades. Rio de Janeiro: Mauad.

Maricato, E. (2001). Brasil, Cidades - Alternativas para a crise urbana. Petrópolis: Vozes. pp. 47-124.

Maricato, E., Vainer, C. \& Arantes, O. (2009). A cidade do pensamento único: desmanchando consensos. Petrópolis: Vozes.

Mendes, L. (2010). O contributo de Neil Smith para uma geografia crítica da gentrificação. E-metropolis, ano 1, n.1, 21-33-, maio de 2010.

Preteceille, E. \& Ribeiro, L. (1999). Tendências de segregação social em metrópoles globais e desiguais: Paris e Rio de Janeiro nos anos 80. RBCS Vol. 14 no 40.

Ribeiro, L. (1997). Dos cortiços aos condomínios fechados: as formas de produção da moradia na cidade do Rio de Janeiro. Rio de Janeiro: Civilização Brasileira; IPPUR/UFRJ; FASE.

Ribeiro, L. \& Cardoso, A. (2003). Plano Diretor e Gestão Democrática da cidade In: Ribeiro, L. \& Cardoso, A. (Organizadores). Reforma Urbana e Gestão Democrática: promessas e desafios do Estatuto da Cidade. Rio de Janeiro: Revan: FASE.

Ribeiro, L. (2003). O Estatuto da Cidade e a questão urbana brasileira. In: Ribeiro, L. \& Cardoso, A. (Organizadores). Reforma Urbana e Gestão Democrática: promessas e desafios do Estatuto da Cidade. Rio de Janeiro: Revan: FASE.

RIO (cidade) (2009). Plano Estratégico da Prefeitura do Rio de Janeiro. Rio de Janeiro.

Sánchez, F. (1999). Políticas Urbanas em Renovação: uma leitura dos modelos emergentes. In: Revista Brasileira de Estudos Urbanos e Regionais. №1.

Sánchez, F. (2010). A reinvenção das cidades para um mercado mundial. 2a edição. Chapecó, SC: Argos.

Santos, M. (2007). O Espaço do Cidadão. 7ạ edição. São Paulo: Edusp.

Souza, M. \& Rodrigues, G. (2004). Planejamento Urbano e Ativismos Sociais. São Paulo: Ed. Unesp. 
Ultramari, C. \& Rezende, D. (2008). Planejamento Estratégico e Planos Diretores Municipais: Referenciais e Bases de Aplicaçăo In: $\underline{\text { RAC - Revista de Administração }}$ Contemporânea v. 12, n. 3, p. 717-739, Curitiba.

Valença, M. (2010a). La Gioconda, a cidade contemporânea e os centros históricos. Arquitextos, 117.02.

Valença, M. (2010b). Justiça social, espaço público e cidade: o pensamento utópico de David Harvey (53-69). In: Leal, S. \& Lacerda, N. (Orgs.). Novos Padrões de Acumulação Urbana na produção do Habitat: olhares cruzados Brasil - França. Recife: ed. Universitária da UFPE.

Villaça, F. (2000). Perspectivas do Planejamento urbano no Brasil hoje. Texto apresentado no II seminário Cidades Brasileiras - Desejos e Possibilidades, organizado pela Prefeitura Municipal de Campo Grande, MS. 